\title{
Mechanism of Action of Nigella sativa on Human Colon Cancer Cells: the Suppression of AP-1 and NF- $x$ B Transcription Factors and the Induction of Cytoprotective Genes
}

\author{
Ayman I Elkady ${ }^{1,2, *}$, Rania A Hussein ${ }^{3,4}$, Sufian M El-Assouli ${ }^{1}$
}

\begin{abstract}
Background and Aims: Colorectal cancer is one of the leading causes of death in the world. The aim of this study was to investigate the growth-suppression potentiality of a crude saponin extract (CSENS) prepared from medicinal herb, Nigella sativa, on human colon cancer cells, HCT116. Materials and Methods: HCT116 cells were subjected to increasing doses of CSENS for 24,48 and $72 \mathrm{~h}$, and then harvested and assayed for cell viability by WST-1. Flow cytometry analyses, cell death detection ELISA, fluorescent stains (Hoechst 33342 and acridine orange/ethidium bromide), DNA laddering and comet assays were carried out to confirm the apoptogenic effects of CSENS. Luciferase reporter gene assays, quantitative reverse transcription-polymerase chain reaction and Western blot analyses were performed to assess the impact of CAERS and CFEZO on the expression levels of key regulatory proteins in HCT116 cells. Results: The results demonstrated that CSENS inhibited proliferation and induced apoptosis. Apoptosis was confirmed by flow cytometry analyses, while CSENS-treated cells exhibited morphological hallmarks of apoptosis including cell shrinkage, irregularity in cellular shape, cellular detachment and chromatin condensation. Biochemical signs of apoptosis, such as DNA degradation, were observed by comet assay and gel electrophoresis. The pro-apoptotic effect of CSENS was caspase-3-independent and associated with increase of the Bax/Bcl-2 ratio. CSENS treatment down-regulated transcriptional and DNA-binding activities of NF- $\varkappa$ B and AP-1 proteins, associated with down-regulation of their target oncogenes, c-Myc, cyclin D1 and survivin. On the other hand, CSENS up-regulated transcriptional and DNA-binding activities of Nrf2 and expression of cytoprotective genes. In addition, CSENS modulated the expression levels of ERK1/2 MAPK, p53 and p21. Conclusions: These findings suggest that CSENS may be a valuable agent for treatment of colon cancer.
\end{abstract}

Keywords: Apoptosis - oncogenes - cytoprotective genes - transfection - qRT-PCR - western blot

Asian Pac J Cancer Prev, 16 (17), 7943-7957

\section{Introduction}

Colorectal carcinoma $(\mathrm{CRC})$ is the third most common form of cancer and the second leading cause of morbidity and mortality in the world (Jemal et al., 2010). Although there have been advances in knowledge regarding the biology of the disease, treatment options for advanced $\mathrm{CRC}$ are limited due to drug resistance and side effects (Macdonald and Astrow, 2001; Rabik and Dolan, 2007).

Although a complex variety of mechanisms underlie carcinogenesis, the great majority of currently known oncoproteins can be assigned to a limited number of pathways or at least be demonstrated to act on these (Schulz, 2005).For example, numerous intracellular signaling cascades converge at the activation of the transcription factors, nuclear factor $-x \mathrm{~B}(\mathrm{NF}-x \mathrm{~B})$ and activator protein-1 (AP-1). These two proteins act independently or coordinately to regulate the expression of wide arrays of genes controlling cellular activities (Kundu and Surh, 2004; Schulz, 2005). In most normal cells, the $\mathrm{NF}-x \mathrm{~B}$ is retained in the cytoplasm as an inactive complex; being activated by various cues, $\mathrm{NF}-\varkappa \mathrm{B}$ translocates into the nucleus, where it binds to its cognate DNA-binding site and activates its target genes (Pereira and Oakley). In contrast, in many human cancer phenotypes including $\mathrm{CRC}, \mathrm{NF}-\varkappa \mathrm{B}$ has been found to be constitutively activated, and sustained activation of $\mathrm{NF}-x \mathrm{~B}$ is closely correlated with resistance of $\mathrm{CRC}$ cells to the apoptosis induced by various chemotherapeutic agents (Yun et al., 2009). Similar to NF- $x$ B, AP- 1 activation has been found to play important roles in various biological processes linked to cell transformation and tumor promotion, progression and metastasis (Hsu et al., 2000). Furthermore, various agents that activate $\mathrm{NF}-\varkappa \mathrm{B}$ also activate AP-1 protein (Gopalakrishnan and Kong, 2009). Activation of AP-1 plays a key role in CRC carcinogenesis and augments chemo- and radio-resistance in human CRC cells (Vaiopoulos et al., 2010). 
Apoptosis is a strictly regulated pathway responsible for the ordered removal of superfluous, aged, and damaged cells (Wong, 2011). Most importantly, a growing body of evidence demonstrates that current cancer therapies, such as chemo-, radio-, immuno- or suicide gene-therapy, primarily exert their antitumor effect by triggering apoptosis in cancer cells (Fulda and Debatin, 2004). However, cancer cells use multiple pathways to evade apoptosis, which underlie the insufficiency of current therapies (Khan et al., 2006; Martin, 2006). Therefore, searching for bioactive agents with the ability to induce apoptosis in cancer cells is a promising option for cancer chemoprevention and/or chemotherapy. In addition to the vital role of apoptosis-inducing agents in chemotherapy, cumulative studies underscore that one of the rational and effective approaches for cancer chemoprevention is the blockade of DNA damage caused by carcinogenic insults. This can be achieved by inducing the activities of phase II detoxifying and stress-responsive antioxidant genes. These genes mediate the expression of xenobiotic metabolizing enzymes that catalyze reactions involved in reducing the formation of reactive carcinogenic species or in stimulating their detoxification (Eggler et al., 2008). The induction of phase II and antioxidant genes is regulated, at least in part, by nuclear transcription factor Nrf2, which is sequestered in the cytoplasm by an inhibitor protein (Surh et al., 2008). Upon exposure of cells to inducers, such as an oxidative stress or electrophilic insult, Nrf2 dissociates from its inhibitor, translocates to the nucleus, binds to the antioxidant response elements (ARE) found in phase II detoxifying and antioxidant genes and activates transcription (Surh et al., 2008). In addition to its role as a master regulator of those genes, numerous lines of evidence suggest that $\mathrm{Nrf} 2$ is a mediator of oncogenesis, being involved in activities related to cell growth control, apoptosis and oncogenic kinase pathways (Gañán-Gómez et al., 2013). Therefore, recent studies verified that Nrf2 is a key molecular target for the chemoprevention of cancer (Yu and Kensler, 2005) and agents that activate Nrf2 are promising candidates for chemotherapy (Surh et al., 2008).

Recently, considerable attention has been focused on dietary and medicinal phytochemicals derived from natural sources, such as herbs used in folk and traditional medicine, as a rich source for discovering novel anticancer agents (Aggarwal et al., 2009). Among natural products, the seeds and oil of Nigella sativa (commonly known as black cumin) have attracted the interest of medical scientists. For more than 2000 years, the black seeds of N. Sativa have been used as a spice and a natural remedy to promote health and treat diseases that include asthma, diarrhea, dyslipidaemia, allergic rhinitis, bronchial asthma, atopic eczema and some cancer phenotypes(Ali and Blunden, 2003; Assim et al., 2010; Khan et al., 2011). Most importantly, numerous studies have shown that the seeds and oil of this herb are characterized by a very low degree of toxicity (Ali and Blunden, 2003). Several classes of compounds have been isolated from the seeds of N. sativa, such as alkaloids, flavonol triglycosides, saponins and an isobenzofuranone derivative (Ahmad et al., 2013). Among these active compounds, much of the biological activities of the seeds have been attributed to thymoquinone, the major component of the essential oil (Banerjee et al., 2010). Accordingly, most researchers have dealt with thymoquinone and its derivatives, as the anticancer bioactive compounds in N. sativa and have paid little attention, if any, to other ingredients, such as saponins, present in the herb.

Saponins are a diverse group of compounds widely distributed in the plant kingdom, and many saponins exhibit cancer chemopreventive and chemotherapeutic activities to inhibit tumor growth in vitro and in vivo, suggesting that they may be promising anticancer agents. For example, soybean saponins have been demonstrated to suppress the growth of colon cancer cells (Gurfinkel and Rao, 2003) and Ginseng saponin metabolite, 20 (S)-protopanaxadiol, exhibited anti-proliferative effects on HCT116 colon cancer cells and reduced tumor size in a xenograft model (Gao et al., 2013). Meanwhile, other saponins such as methyl protoneogracillin, methyl protogracillin, protoneodioscin and protodioscin have been identified as potential anticancer agents by the National Cancer Institute's (NCI) anticancer drug screening program (Guclu-Ustundag and Mazza, 2007).

Though the presence of huge amounts of saponin compounds in N. sativa has been reported, any study regarding their anti-cancer activity has not been reported yet.Based on the abovementioned studies and considering the fact that in some cases herbal extracts are showing more potency than the purified components (Seeram et al., 2004; 2006), this study was undertaken. We investigated the anti-proliferative potentiality of the crude saponin extract of $\mathrm{N}$. sativa on human colon cancer cells, HCT116, and further elaborated the molecular mechanism underlying this action.

\section{Materials and Methods}

Unless otherwise noted, all chemicals were purchased from Sigma.

\section{Preparation of crude extracts}

Crude saponin extract of N. sativa was essentially prepared as described previously (Elkady and El-Hamidy, 2013). After preparation, the stock was further diluted in water to give the final indicated concentrations and was termed as crude saponin extract of N. sativa (CSENS). For crude alkaloid of $\mathrm{N}$. sativa (CAENS), dried seeds of $\mathrm{N}$. sativa $(250 \mathrm{~g})$ were soaked in $75 \%$ ethanol $(1 \mathrm{~L})$ at ambient temperature for 3 days after which the alcoholic extract was evaporated in a rotatory evaporator and the remaining residue was suspended in water and then filtered. Then the aqueous extract was handled as previously detailed (Elkady et al., 2013). The crude flavonoid extract of $\mathrm{N}$. sativa (CFENS) was prepared as detailed in our previous study (Elkady et al., 2014) with one modification, where the starting material was ground seeds of N. sativa rather than ground rhizome of Zingibarofficinale. The crude alkaloid extract of Rhazyastricta (CAERS) was prepared as detailed in our previous study (Elkady et al., 2014).

Phytochemical examination for testing the presence of saponins in CSENS was adapted from Trease and Evans (Trease and Evans, 2002). The extract (2 mL) was 
mixed and shaken with $5 \mathrm{~mL}$ water; the formation of foam for $15 \mathrm{~min}$ is an indication of the presence of saponins. Phytochemical examinations for testing the presence of alkaloids and flavonoids were carried out as described in our previous study (Elkady et al., 2014).

\section{Cell viability, clonogenic and soft agar colony-forming assays}

The human CRC (HT116), breast cancer (MCF7), hepatocellular (HepG2) and non-malignant human foreskin fibroblast (HF-5) cell lines were obtained from the King Fahd Center for Medical Research, King Abdulaziz University, Saudi Arabia. Cell viability and the effects of CSENS extract on the growth of HCT116 cells were assessed byWST-1 Cell Proliferation Assay Kit (Cayman Chemicals, USA) according to the manufacturer's instructions. Briefly, HCT116 cells were seeded onto 96-well plates $\left(10^{4}\right.$ cells/well) and grown overnight. The cells were then treated with indicated concentrations of the extracts and incubated for 24,48 or $72 \mathrm{~h}$. At the end of each incubation, $10 \mu \mathrm{l}$ of freshly prepared WST-1 solution was added to each well. The culture medium and WST-1 solution were added in an empty well as a blank for the microtiter plate reader. The absorbance of the treated and untreated samples was measured after 2 h by a micro plate reader (BioTek Synergy HT), at 450 $\mathrm{nm}$ with a reference wavelength of $630 \mathrm{~nm}$ to avoid the interference of cell layer absorbance that blocks light passing through. Clonogenic and soft agar colony-forming assays were essentially carried out as previously described (Elkady et al., 2014).

\section{Apoptosis assays}

Cellular DNA fragmentation ELISA assays were performed using the kit according to the manufacturer's instructions (Roche Molecular Biochemicals, Mannheim, Germany). Briefly, HCT116 cells were seeded in 96-well round bottom plate $\left(10^{4}\right.$ cells/well) and incubated for 12 $\mathrm{h}$ at $37^{\circ} \mathrm{C}$ with the non-radioactive thymidine analog 5-bromo-2'-deoxyuridine (BrdU). Then, BrdU-containing culture medium was discarded and labeled cells were resuspended in BrdU-free culture medium and treated with the indicated concentrations of CSENS for $24 \mathrm{~h}$. Supernatants were collected and saved to measure the level of labeled DNA fragments in late apoptotic/necrotic cells. Subsequently, cells were lysed and transferred to a microtiter plate coated with an anti-DNA antibody; then, anti-BrdU-peroxidase conjugate solution was added to each well, and the plate was incubated for $90 \mathrm{~min}$ at room temperature. The plate was then washed, substrate solution was added, and the plate was incubated in the dark on a shaker until color development was sufficient. The reaction was then stopped by adding $25 \mu 1$ of 0.56 $\mathrm{M} \mathrm{H} 2 \mathrm{SO} 4$. The absorbance was measured at 450 and $655 \mathrm{~nm}$ for each well using a microplate reader (BioTek Synergy HT).

For flow cytometry analyses, HCT116 cells were seeded in 6-well plates $\left(200 \times 10^{3}\right.$ cells/well $)$ and treated with indicated concentrations of CSENS extracts for $24 \mathrm{~h}$. Then, cells were collected and washed in PBS; cell pellets were resuspended in $500 \mu \mathrm{l}$ of $1 \mathrm{X}$ Binding Buffer. Next, 5 $\mu \mathrm{l}$ of Annexin V-FITC and $10 \mu \mathrm{l}$ of propidium iodide were added and cells were incubated at room temperature for 15 min in the dark. The cells were then analyzed immediately by flow cytometry (Beckman Coulter).

\section{Nuclear and cytoplasmic staining assays}

The nuclear morphological changes associated with apoptosis were analyzed using Hoechst 33342 or acridine orange/ethidium bromide staining. HCT116 cells were suspended at a final concentration of $150 \times 10^{3}$ cells/well and cultured above a $35 \mathrm{~mm}$ slip in 6-well flat-bottomed plates and allowed to adhere to the bottom of the wells for $24 \mathrm{~h}$ before CSENS treatment. Cells were then exposed to indicated concentrations of the CSENS for $24 \mathrm{~h}$, before being washed with PBS and stained with Hoechst 33342 or acridineorange/ethidium bromide for $15 \mathrm{~min}$ at $37^{\circ} \mathrm{C}$. Subsequently, cells were washed with PBS and viewed under fluorescence microscope (Axioplan 2 Zeiss, Germany).

\section{Single-cell gel electrophoresis (comet) and DNA} fragmentation assays

For single-cell gel electrophoresis (Comet) and DNA fragmentation assays, cells were treated with indicated concentrations of CSENS for $24 \mathrm{~h}$ in complete medium, harvested, resuspended in ice-cold PBS and processed as described in our previous study (Elkady et al., 2014).

\section{Caspase activity assays}

Caspase- $3 / 7$ activities were determined by using the Apo-ONE ${ }^{\circledR}$ Homogeneous Caspase-3/7 Assay (Promega). HCT116 cells were seeded on a 96-well luminometer plate $\left(10^{4}\right.$ cells/well $)$ and treated with indicated concentrations of CSENS for $24 \mathrm{~h}$. Then, activities of Caspase-3/7 were measured according the manufacturer's instructions. Briefly, $100 \mu \mathrm{l}$ of Apo-ONE ${ }^{\circledR}$ Caspase-3/7 reagent was added to each well and the contents of the wells were mixed using a plate shaker at 300-500 rpm for $12 \mathrm{~h}$. The fluorescence of each well was measured using a microplate reader (BioTek Synergy) with excitation at 485/20 $\mathrm{nm}$ and emission at 528/20 $\mathrm{nm}$.

\section{Transient transfection and luciferase activity assays}

HCT116 cells $\left(40 \times 10^{3}\right.$ cells/well) were plated in 24well plates and transiently transfected with either pNF$\varkappa$ B-Luc, pAP-1-Luc plasmid (Stratagene) or Nrf2 Cignal reporter (QIAGEN) using Lipofectamine ${ }^{\circledR} 2000$ according to the manufacturer's specifications (Invitrogen, Carlsbad, CA, USA). For normalization, cells were co-transfected with $10 \mathrm{ng} /$ well of the Renilla luciferase reporter hRLTK (Promega). The transfected cells were treated with indicated concentrations of CSENS for $24 \mathrm{~h}$. Luciferase activity was measured using the dual-luciferase reporter assay system (Promega), according to the manufacturer's instructions.

Detecting DNA-binding activities of $N F-\varkappa B, A P-1$ and Nrf-2 proteins

For measuring the DNA-binding activities of NF- $x \mathrm{~B}$, AP-1 and Nrf-2 proteins, HCT116 cells were seeded in 6-well plates $\left(20 \times 10^{4} \mathrm{cells} /\right.$ well $)$ and treated with indicated 
concentrations of CSENS extracts for $24 \mathrm{~h}$. Then, cells were collected and nuclear extracts were prepared using NE-PER ${ }^{\circledR}$ Nuclear and Cytoplasmic Extraction Reagents (Thermo Scientific), and protein concentration was quantitated using Pierce ${ }^{\mathrm{TM}}$ BCA Protein Assay Kit (Thermo Scientific), following the manufacturers' instructions. DNA-binding activities of the NF- $x \mathrm{~B}, \mathrm{AP}-$ 1 , and Nrf2 were assessed using the TransAm Active Transcription Factor Assay Kit (Active Motive, USA), following the manufacturer's instructions. Three assay kits were used, TransAMTM NF- $\varkappa$ B family kit, TransAM ${ }^{\mathrm{TM}}$ AP-1 family kit and TransAM ${ }^{\mathrm{TM}}$ Nrf2 family kit. Briefly, $10 \mu \mathrm{g}$ of nuclear protein samples were incubated overnight at $4^{\circ} \mathrm{C}$, without shaking in a 96-well plate coated with a binding site for either NF- $\varkappa \mathrm{B}, \mathrm{AP}-1$, or Nrf2, to which activated NF- $x$ B/p65, Ap-1/c-Fos, Ap-1/c-Jun or Nrf2 in nuclear extracts specifically binds. The plates were extensively washed according to the manufacturer's instructions and incubated with primary antibody raised against NF- $x$ B/p65, Ap-1/c-Fos, Ap-1/c-Jun or Nrf2. The plates were then washed and incubated with secondary antibody, horseradish peroxidase (HRP)-conjugated antibody; specific binding was detected by colorimetric estimation at $450 \mathrm{~nm}$ and normalized to the background readings.

\section{Quantitative RT-PCR}

Cells were seeded $\left(20 \times 10^{4} /\right.$ well $)$ onto 6 -well plates and treated with indicated concentrations of CSENS for $24 \mathrm{~h}$. After this period, floating and adherent cells were collected, washed with PBS and pelleted by centrifugation (700 g, $5 \mathrm{~min}$ ). For RNA extraction and reverse transcriptase-PCR, gene-specific primers were used as previously described (Elkady et al., 2013).

\section{Western blot analysis}

For Western blot analysis, polyacrylamide gel electrophoresis and immunoblotting were performed as previously described (Elkady et al., 2013).

\section{Statistical analysis}

All experiments were repeated from three to five times independently and in triplicate. The results were presented as mean \pm standard deviation (SD) for continuous variables. The statistical significance of results was determined by Student's t-test, and a $p$ value of more than 0.05 was considered statistically significant.

\section{Results}

CSENS inhibits cell proliferation and colony growth in HCT116 cells

Initially, we independently assessed the effects of CSENS, CFENS and CAENS on the growth of HCT116 cells. The cells were incubated with increasing concentrations $(0,75,100,125$ and $150 \mu \mathrm{g} / \mathrm{mL})$ of each extract for 24, 48 and $72 \mathrm{~h}$, before being harvested and assayed for cell viability by WST-1 Cell Proliferation Assay Kit. The results summarized in [Figure 1A] demonstrate that only CSENS, but not CFENS or CAENS, has an anti-proliferation potentiality. This is because CSENS efficiently inhibited cell viability in dose- and time-dependent manner. Calculated $\mathrm{IC}_{50}\left(\mathrm{IC}_{50}\right.$, the concentration of test compound that inhibits $50 \%$ of the cell growth) after 24,48 and $72 \mathrm{~h}$ of incubation with the CAERS were 150,125 and $85 \mu \mathrm{g} / \mathrm{mL}$, respectively.

To this end, a question was raised whether CSENSdependent growth inhibition was selective toward colon cancer cells, HCT116. This question was addressed by repeating the above experiments using other human
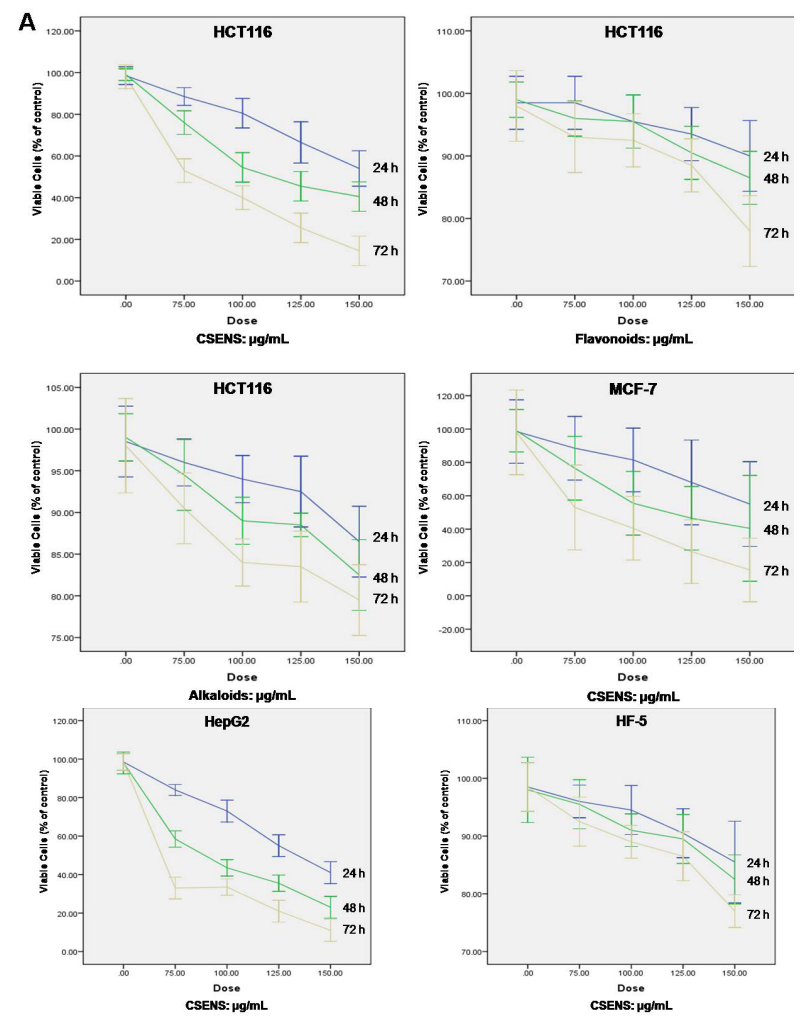

B

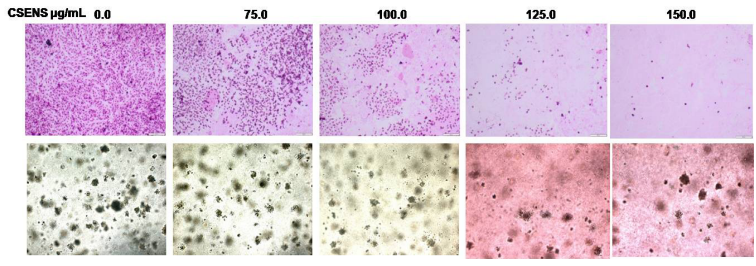

Figure 1. CSENS Inhibits Cell Proliferation and Colony Growth in HCT116 Cells. (A) The displayed cell lines were seeded, at a density of $10^{4} /$ well in 96 wells plates and treated with the indicated concentrations of CSENS for the displayed and time intervals. The inhibition of cell proliferation was assessed by the tetrazolium salt WST-1 kit as detailed in section Materials and Methods. The experiments were repeated five times in triplicates, and cell viabilities at each dose of extract(s) were expressed in terms of percent of control and reported as the mean $\pm \mathrm{SD}$. (B) HCT116 cells were seeded onto a 6-well plate at 1000 cells/well and treated with the indicated concentrations of CSENS as has been detailed in Materials and Methods. The colonies were counted under a dissection microscope and the experiment was repeated three times. (C) CSENS inhibited anchorage-independent growth in HCT116 cells in growth in soft agarose assays. HCT116 cells were plated, in triplicate, in $0.35 \%$ soft agarose and treated with the indicated concentrations of CSENS as has been detailed in Materials and Methods. After 2 weeks, the colonies were stained with $0.0005 \%$ crystal violet and photographed. Representative images of colonies in soft agar are shown 
cancer cell lines, including breast and hepatic cancer lines MCF-7 and HepG2, respectively, as models. As shown in Figure 1A, CSENS recapitulated its growthinhibitory potentiality in the contexts of MCF-7 and HepG2 cells, in a dose- and time-dependent manner. To find out whether CSENS-dependent growth inhibition was selective toward cancer cells, we assessed the effect of CSENS on viability of non-malignant human foreskin fibroblasts, HF-5 cells. As can be seen in Figure 1A, the HF-5 cell line was significantly more resistant to growth inhibition by CSENS. The strongest effect was seen at the highest dose of the CSENS, where survival of HF-5 cells was inhibited by only $20 \%$ on a $72-\mathrm{h}$ exposure. These data suggest that CSENS has a cytostatic/cytocidal effect, selectively, on cancer cells.

Next, we determined the effect of CSENS on colony formation (clonogenicity assay) in HCT116 cells. This assay provides an indirect estimation of the tendency of tumor cells to undergo neoplastic transformation. The HCT116 cells were plated at low density, treated with increasing doses $(0,75,100,125$ and $150 \mu \mathrm{g} / \mathrm{mL})$ of CSENS and maintained in culture for 14 days to allow the formation of colonies. Figure 1B shows that CSENS

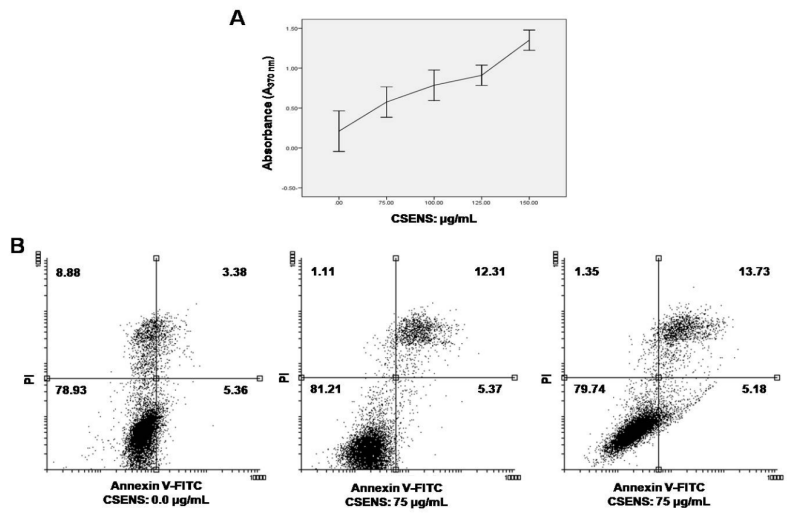

Figure 2. CSENS Treatments Induces Apoptosis in HCT116 Cells. (A) Cellular DNA fragmentation ELISA assays; HCT116 cells were seeded in 96-well round bottom plate $\left(10^{4}\right.$ cells/well) and incubated for $12 \mathrm{~h}$ at $37^{\circ} \mathrm{C}$ with the nonradioactive thymidine analog 5-bromo2'-deoxyuridine (BrdU). Then, BrdU-containing culture medium was discarded and labeled cells were resuspended in BrdU-free culture medium and treated with the indicated concentrations of CSENS for $24 \mathrm{~h}$ before being assayed as detailed in Materials and Methods. Values present the mean of triplicates \pm S.D. and each experiment was performed three times. (B) Dot plots display the apoptotic death of HCT116 cells evaluated by flow cytometry. The cells were treated with indicated concentration of CSENS, stained with monoclonal antibodies against Annexin V-FITC and PI. Cells in left lower quadrants represent viable population (Annexin V-negative and PI-negative); cells in right lower quadrants represent early apoptotic population (Annexin V-positive, PI-negative); cells in right top quadrants represent late apoptotic population (Annexin V-positive and PI-positive) and cells in left top quadrants represent necrotic population (Annexin V-negative and PI-positive). was able to reduce both the numbers and sizes of growing colonies, in a dose-dependent manner.

To further validate the effect of CSENS extract on HCT116 colony formation, we carried out Agar colonyforming assays. This assay is used to measure the ability of cells to grow in soft agar in an anchorage-independent manner. In this assay, cells are seeded in a soft agar media matrix, where they are unable to attach to an underlying substrate. If cells are able to proliferate, they will grow and form colonies. As seen in Figure 1B, the growth of untreated HCT116 cells on soft agar was noticeable; in contrast, the treatment of HCT116 cells with CSENS inhibited the growth of colonies. These data suggest that CSENS extract has the ability to inhibit anchoragedependent and -independent growth of HCT116 colon cancer cells .

\section{CSENS treatments inhibit DNA synthesis and induce apoptosis in HCT116 cells}

There are two principal scenarios to reduce the number of cells in a cell population; cell death or inhibition of proliferation. As most phytochemical agents mediate their chemopreventive potentialities via inhibition of cell proliferation[19], we assumed that the reduction of cell number in the aforementioned experiments is due to the inhibition of proliferation. To confirm this assumption, we determined the rates of DNA synthesis. Figure 2A shows that the incubation of HCT116 cells with escalated doses of CSENS increased the appearance of DNA fragments in the HCT116 cells indicating that CSENS impaired the DNA synthesis pathway. Therefore, these experiments suggest that CSENS suppressed the growth of HCT116 cells via inhibition of cell proliferation.

One of the targets of chemopreventive potentialities of phytochemicals is the induction of apoptosis in cancer cells[13]. Thus, we tested whether CSENS has an apoptogenic potentiality. To achieve this goal, we employed flow cytometry analyses to measure the fluoresce intensity of Annexin V FITC and propidium iodide (PI) in cells treated with CSENS. This assay is a marker for assessing early stages of apoptosis and helps to distinguish between apoptotic and necrotic cell death. We treated the cells with CSENS for $24 \mathrm{~h}$ and measured the Annexin V FITC/PI staining responses by flow cytometry. In the cytometry images (Figure 2B), viable cells appear negative for both PI and Annexin V (left bottom quadrants); early apoptotic cells appear positive for Annexin V and negative for PI (right bottom quadrants); whereas late apoptotic/necrotic cells display both high Annexin V and PI labeling (right top quadrants); non-viable cells undergoing necrosis are positive for PI and negative for Annexin V (left top quadrants). We observed that CSENS treatments resulted in a significant elevation in the percentage of Annexin V-FITC (+)/PI(+) cells (upper right quadrant), in a concentration-dependent manner. The percentages of Annexin V and PI positive cells were $(3.38 \pm 2.2) \%,(12.31 \pm 2.6) \%$ and $(13.73 \pm 3.8) \%$ in 0,75 and $100 \mu \mathrm{g} / \mathrm{mL}$ CSENS, respectively. Therefore, this assay demonstrates the emergence of late apoptotic (or secondary necrotic) death in treated cells, and we concluded that CSENS has a potentiality to trigger 
apoptosis.

\section{CSENS treatments induce morphological features of apoptosis}

To confirm that CSENS induced apoptotic cell death, we assessed its morphological hallmarks in treated cells. Thus, cells were treated with increasing concentrations of CSENS for $24 \mathrm{~h}$, and the frequency of programmed cell death was initially assessed by phase contrast microscopy. As seen in Figure 3A, untreated HCT116 cells appeared adherent and assumed a normal epithelial morphology forming a confluent monolayer. In contrast, CSENStreated cells appeared much more readily detached and exhibited rounded-up, balloon-like shapes. Next, we further ascertained the pro-apoptotic effect of CSENS by Giemsa stain, where we noticed the emergence of apoptotic signs in treated cells, in a dose-dependent manner. As shown in Figure 3B, while control cells appeared with a homogenous morphology containing lightly and evenly stained nuclei, CSENS-treated cells exhibited characteristic features of apoptosis. These include cellular shrinking, membrane blebbing and condensation of the peripheral heterochromatin and cleavage of the nucleus and cytoplasm into multiple membrane-enclosed apoptotic bodies. As it has been cited that some phytochemicals might exert their anti-proliferative potentiality via induction of necrosis (see Discussion), we treated the cells with the highest dose $(150 \mu \mathrm{g} / \mathrm{mL})$ of CSENS for $72 \mathrm{~h}$ and we monitored their morphological changes. We observed the characteristics of secondary necrosis in some treated cells; these include cellular swelling, loss of membrane integrity with leaking cell contents, clear vesicles in the cytoplasm and eventually, cellular and nuclear lysis (Figure 3B). Therefore, we concluded that long- time exposure or application of high doses of CSENS might induce necrosis.

Next, we watched the nuclear changes in HCT116 cells after CSENS treatment utilizing a fluorescent nuclear stain Hoechst 33342. In untreated cells, the nuclei fluoresced a faint green homogenous color, while in the treated cells, the green emission was much brighter than in the unaffected ones owing to chromatin condensation (Figure 3C). Although most CSENS-treated cells showed nuclear clumps of condensed chromatin, indicative of apoptosislike changes, we could not see a nuclear fragmentation, suggesting that cell death induced by CSENS does not have the characteristics of classical apoptosis (Figure 3C).

Staining of apoptotic cells with fluorescent dyes such as acridine orange (AO) and ethidium bromide (EB) is considered the correct method for evaluating the changed nuclear morphology. In this assay, only AO, but not EB, can cross the plasma membrane of vital cells and stain nuclei green. When the plasma membrane is disrupted at late apoptotic phase or due to necrosis, EB can also enter the cell and stain the nuclei red. Based on this, live cells will show a normal green nucleus. Early apoptotic cells show bright green nucleus owing to condensation of chromatin, while necrotic cells show intact normal red nucleus. Our results depicted in Figure 3D indicate that the nuclei of untreated control cells were found to be intact, round in shape and were stained green. On the other hand,

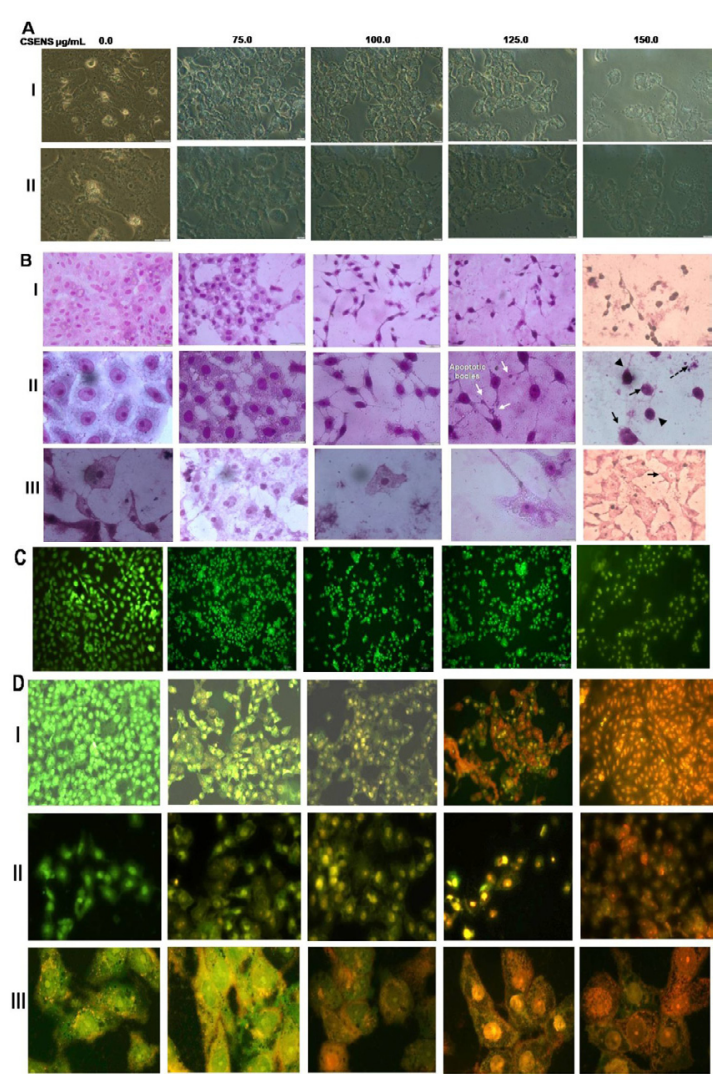

Figure 3. CSENS Treatments Induced Characteristic Features of Apoptosis in HCT116. The cells were treated with the indicated concentrations of CSENS for $24 \mathrm{~h}$, after which cells were examined for emergence of apoptotic hallmarks. (A) Phase contrast microscope images showing morphological changes in HCT116 cells after incubation with CSENS; magnification: 20x (I) and 40x (II). (B) Light microscope images displaying cells fixed in formalin-buffered phosphate and stained with Giemsa stain; notice gradual alteration of cell shapes as a result of increasing doses of CSENS. These include cellular shrinkage (second and third panels), irregularity of cell shape and blebbing of cell membrane (fourth panel), condensation of chromatin, apoptotic bodies and late apoptosis/secondary necrosis (solid arrows, fifth panel); magnification as following: 40x (I) and 60x (II). In third row (III), emergence of necrotic cell death was observed in HCT116 cells incubated with $150 \mu \mathrm{g} / \mathrm{ml}$ of CSENS for $72 \mathrm{~h}$. Notice hallmarks of necrotic cell death; these include cellular swelling (first panel), often accompanied by loss of membrane integrity (second panel) leaking cell contents (third panel), clear vesicles in the cytoplasm (fourth panel) and eventually cellular and nuclear lysis (fifth panel); magnification 100x. (C) Cells were stained with vital nuclear stain (Hoechst 33342 ) for $15 \mathrm{~min}$ at $37^{\circ} \mathrm{C}$ and visualized by florescent microscope. Note control cells presented homogeneously stained green nuclei of chromatin while nuclei of treated cells stained bright green, indicating chromatin condensation; magnification 20x. (D) Cells stained with $1 \mu \mathrm{g} / \mathrm{ml}$ acridine orange/ethidium bromide for $15 \mathrm{~min}$ at $37^{\circ} \mathrm{C}$ and visualized by florescent microscope. At onset of apoptosis viable cells stain uniformly green (75 CSENS $\mu \mathrm{g} / \mathrm{mL}$ ), early apoptotic cells with intact plasma membranes appear green, with "dots" of condensed chromatin that are highly visible at $100 \mathrm{CSENS} \mu \mathrm{g} / \mathrm{mL}$, at middle stage of apoptosis cells are stained bright green-orange because plasma membrane losses its integrity, ethidium bromide can enter the cell (125 CSENS $\mu \mathrm{g} / \mathrm{mL})$ and at late stage of apoptosis late apoptotic/necrotic nonviable cells are stained red due to the entry of ethidium bromide into these cells (150 CSENS $\mu \mathrm{g} / \mathrm{mL}$ ). Magnification as following: 20x (I), 40x (II) and 1000x (III) 


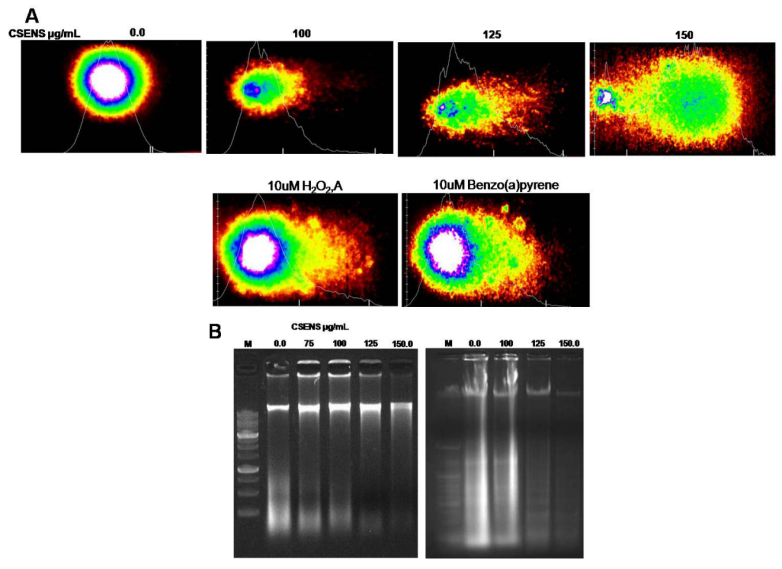

Figure 4. CSENS Treatments Induce DNA Breakage Lacking Oligonucleosomal Degradation. HCT116 cells were treated with the indicated concentration of CSENS for $24 \mathrm{~h}$, harvested and assayed. (A) Comet assay showing DNA damage in HCT116 cells treated with CSENS; analysis of comet images was performed using Extended dynamic range imaging (EDRI) technology. At $100 \mu \mathrm{g} / \mathrm{mL}$ CSENS, cells displayed mean tail moment 1.4 ; at $125 \mu \mathrm{g} / \mathrm{mL}$ CSENS, cells displayed mean tail moment 2.8 , and at $150 \mu \mathrm{g} / \mathrm{mL}$ CSENS, cells displayed mean tail moment 7.4. Notice the last image shows clear appearance of a fan like comet formation, which is a typical characteristic of apoptotic phenomenon. The lower panels show necrotic effect of $\mathrm{H}_{2} \mathrm{O}_{2}(10 \mathrm{uM})$ and Benzo (a)pyrene (10uM). The cells were treated with $\mathrm{H}_{2} \mathrm{O}_{2}$ or Benzo(a)pyrene, then subjected to single cell gel electrophoresis under alkaline conditions and analyzed by comet analysis system based on extended dynamic range imaging (EDRI) technology. (B) Agarose gel images showing DNA laddering in cells undergoing apoptosis; Left panel, agarose gel showing CSENS treatments did not induce oligonucleosomal degradation in HCT116 cells. Right panel, agarose gel showing crude alkaloid extract prepared from medicinal herb, R. stricta, did induced oligonucleosomal degradation in HCT116 cells. Lane ' $\mathrm{M}$ ' indicates the DNA marker ladder

cells treated with 75 and $100 \mu \mathrm{g} / \mathrm{mL}$ CSENS had some cells stained green and some orange nuclei indicating an emergence of early apoptotic signs in the treated cells. At the highest doses of CSENS (125 and $150 \mu \mathrm{g} /$ $\mathrm{mL}$ ), an increase in the number of cells with red-colored nuclei (necrotic/late apoptotic) was predominant. Thus, the morphological analysis of AO/EtBr stained HCT116 cells indicated significant morphological changes. These independent assays (phase contrast microscopy, Giemsa stain, Hoechst 33342 and $\mathrm{AO} / \mathrm{EtBr}$ staining) for assessing apoptosis provided similar results, suggesting that the anti-proliferative potential of CSENS is coupled with its ability to induce apoptosis in HCT116 cells.

\section{CSENS treatments induce DNA breakage lacking oligonucleosomal degradation}

Degradation of DNA is an irreversible event in apoptotic cascade events (Broker et al., 2005). To find whether CRENS treatment may induce DNA degradation, we carried out comet assay. This assay is a sensitive method for monitoring single strand (ss) DNA breaks at the single cell level and used as a biomarker of apoptosis (Collins, 2002). As shown in Figure 4A, treatment of HCT116 cells with increasing doses of CSENS for 24

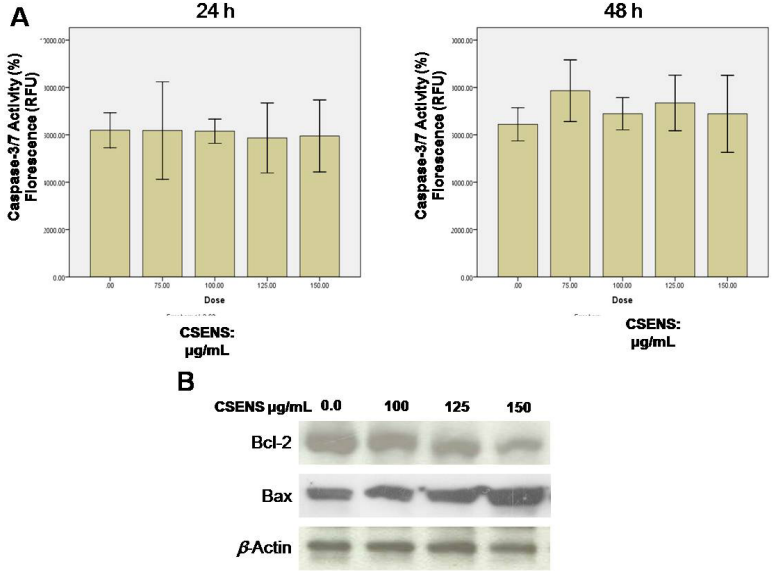

Figure 5. CSENS Induces Apoptosis In HCT116 Via A Caspase-Independent Pathway and Increasing Bax/ Bcl-2 Ratio. (A) HCT116 cells were seeded on a 96-well luminometer plate $\left(10^{4}\right.$ cells/well) and treated with indicated concentrations of CSENS for 24 or $48 \mathrm{~h}$. Then, activities of Caspase-3/7 were measured using Caspase-3 Fluorometric Assay, Apo-ONE Caspase-3/7 Homogeneous Assay Kit (promega) as detailed in Section Materials and Methods. Values present the mean of triplicates \pm S.D. and each experiment was performed three times. (B) Immunoblot showing CSENS treatment altered expression ratio of $\mathrm{Bax} / \mathrm{Bcl}-2$ proteins, in favor of apoptosis

$\mathrm{h}$ resulted in significant DNA damage compared with control cells; the comet tails of the treated cells show the extent of DNA migration out of the nucleus due to DNA breakage and loss of structure. We estimated the length of the comet tail using Extended Dynamic Range Imaging (EDRI) technology; we found that the comet tail moment increased from 0.03 in the control to 1.4, 1.8 and 7.6 at doses of 100, 125 and $150 \mu \mathrm{g} / \mathrm{mL}$ CSENS, respectively. In addition, at the highest dose, the comet head showed a typical apoptotic head (stained clusters of apoptotic bodies) and the comet tail clearly showed a fan-like comet shape, which are typical characteristics of apoptotic phenomenon (Chakraborty et al., 2006). It has been demonstrated that necrotic/genotoxic agents can induce comet tail; nonetheless, the comet image generated by an apoptosis-inducing agents is different from that obtained with a cell treated with necrotic/genotoxic agents. Thus, to further prove that comet images induced by CSENS are related to its ability as an apoptogenic, rather than being a genotoxic agent, we treated HCT116 cells with known genotoxic agents, $\mathrm{H} 2 \mathrm{O} 2$ and $\mathrm{Benz}(\mathrm{a})$ pyrene, and we compared the comet shapes in all cases. We noticed a difference regarding the head and tail shapes between CSENS and genotoxic agents, where the latter did not generate either a typical apoptotic head or a fan-like comet shape. Based on these findings, we concluded that CSENS has a potentiality to trigger DNA damage, and consequently, apoptotic events in HCT116 cells.

The degradation of DNA into oligonucleosomal fragments of multiples of 180 base pairs is an essential feature of classical programmed cell death (Nagata, 2000). Therefore, we examined whether CSENS might induce DNA fragmentation in HCT116 cells. Thus, genomic 

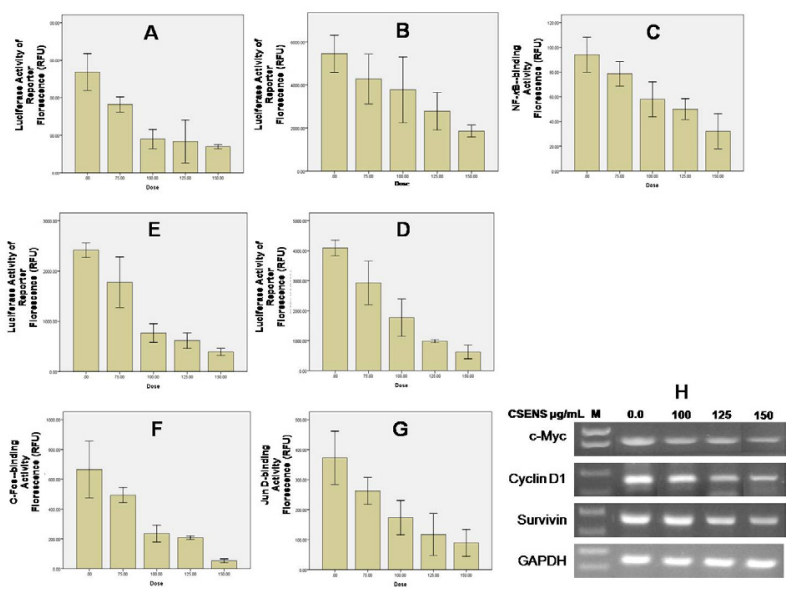

Figure 6. CSENS Inhibits Transcriptional and DNABinding Activities of NF- $x$ B and AP-1 Proteins. (A-C) CSENS Inhibits Transcriptional and DNA-binding Activities of NF- $\varkappa$ B. (A)HCT116 cells were transfected with a plasmid reporter construct (pNF- $x \mathrm{~B}-\mathrm{Luc}$ ) containing NF- $x \mathrm{~B}$ binding sites linked to the firefly luciferase reporter gene. (B) Cells were co-transfected with the $\mathrm{pNF}-\varkappa \mathrm{B}$-Luc reporter along with an upstream kinase MEKK expression construct (pFC-MEKK). (C) Cells were treated with the indicated concentrations of CSENS for $24 \mathrm{~h}$; then nuclear extracts were prepared and DNA-binding activity of NF- $\varkappa \mathrm{B}$ was performed on $10 \mu \mathrm{g}$ of nuclear extract using TransAm Active Transcription Factor Assay Kit as detailed in Materials and Methods. (D-G) CSENS inhibits transcriptional and DNA-binding activities of AP-1. (D) HCT116 cells were transfected with a plasmid reporter construct (pAP-1-Luc) containing AP-1 binding sites linked to the firefly luciferase reporter gene. (E) Cells were co-transfected with the AP-1-Luc reporter along with an upstream kinase MEKK expression construct (pFC-MEKK). To normalize for transfection efficiencies (in A, B, D and E), cells were also cotransfected with $5 \mathrm{ng} /$ well of the Renilla luciferase reporter plasmid. 24-h post-transfection, cells were treated with indicated concentrations of CSENS for $24 \mathrm{~h}$, then cells were harvested and assayed for luciferase level as has been detailed in Materials and Methods. Firefly activities were corrected for Renilla activities and expressed as adjusted RLU. (F and G) CSENS inhibits DNA-binding activities of AP-1 heterodimer, c-Fos (C) and Jun D (D). Cells were treated with the indicated concentrations of CSENS for $24 \mathrm{~h}$; then nuclear extracts were prepared and DNAbinding activities of c-Fos and Jun D was performed on $10 \mu \mathrm{g}$ of nuclear extract using TransAm Active Transcription Factor Assay Kit as detailed in Materials and Methods. (H) CSENS treatments modulated the expression levels of the displayed gene products. After CSENS treatments total RNA was isolated, reverse-transcribed, and subjected to PCR with gene-specific primers. The PCR products of the genes were then subjected to electrophoresis in $1 \%$ agarose gels and visualized by staining with ethidium bromide. GAPDH was used as the internal control, M, DNA ladder

DNA was extracted from cells treated with CSENS and separated by agarose gel electrophoresis. Figure 4B shows that there was no DNA fragmentation in samples from cells treated with CSENS. Previously, we demonstrated that a crude alkaloid extract prepared from another medicinal herb, Rhazyastricta, led to oligonucleosomal DNA fragmentation in HCT116 and other cell lines[32]. So, to confirm that the failure to detect oligonucleosomal DNA fragmentation in response to CSENS was not due to an intrinsic fault in the classical apoptotic cascade in
A

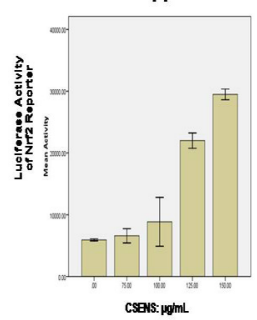

Figure 7. CSENS Enhances Transcriptional and DNABinding Activities of Nrf2. (A) The ability of CSENS to inhibit constitutive transcriptional activity of Nrf2-dependent gene expression was determined by luciferase reporter gene assay. HCT116 cells were transfected with the Nrf2 reporter construct containing ARE-response element linked to the firefly luciferase reporter gene. To normalize for transfection efficiencies, cells were also cotransfected with $5 \mathrm{ng} /$ well of the Renilla luciferase reporter plasmid. 24-h post-transfection, cells were treated with indicated concentrations of CSENS for $24 \mathrm{~h}$, then, cells were harvested to assay luciferase level as has been detailed in Materials and Methods. Firefly activities were corrected for Renilla activities and expressed as adjusted RLU. (B) CSENS enhances DNA-binding activity of Nrf2. Cells were treated with the indicated concentrations of CSENS for $24 \mathrm{~h}$; then nuclear extracts were prepared and DNA-binding activity of Nrf2 was performed on $10 \mu \mathrm{g}$ of nuclear extract using Trans Am Active Transcription Factor Assay Kit as detailed in Materials and Methods. (C) CSENS enhanced expression levels of the HO-1, NQO1 and UGT1A1genes in HCT116 cells. The cells were treated with the indicated concentrations of CSENS for 24; then total RNA was isolated, reverse transcribed and subjected to PCR with gene-specific primers. GAPDH was used as the internal controls for the RT PCR. The data are representative of three independent experiments

HCT116 cells, we treated HCT116 cells with the crude alkaloid extract of R.strictaand we observed the formation of a classical DNA ladder (Figure 4B). Therefore, we concluded that CSENS employs a non-classical DNA fragmentation scenario to process chromatin during apoptosis.

CSENS induces apoptosis in HCT116 via a caspaseindependent pathway and increasing Bax/Bcl-2 ratio

Apoptosis can advance either via caspase-dependent or independent signaling pathways (Broker et al., 2005), therefore, the involvement of caspase-3/7 in CSENS-induced HCT116 cell apoptosis was assessed. HCT116 cells were incubated for $24 \mathrm{~h}$ with increasing concentrations of CSENS and the activity of caspase-3/7 was assayed by Apo-ONE® Homogeneous Caspase-3/7 Assay Kit. The data depicted in Figure 5A demonstrate that there was no difference in caspase-3/7 activity between CSENS-treated and control cells even after treatment either for $24 \mathrm{~h}$ or $48 \mathrm{~h}$. These data suggest that CSENSinduced cell death is not associated with the caspasedependent apoptotic signaling cascade.

In addition to caspases, apoptosis is tightly regulated by the Bcl-2 family of proteins, such as Bcl-2 and Bax[11]. To this end, we employed Western blotting to examine the changes in the expression levels of the Bcl-2 (antiapoptotic) and Bax (pro-apoptotic) following CSENS 
Nigella sativa Extract Inhibits Proliferation and Enhances Apoptosis of Colon Cancer Cells

treatments. As shown in Figure 5B, CSENS treatments highly increased the expression of Bax and concomitantly reduced the expression of $\mathrm{Bcl}-2$ so as to favor apoptosis. These results are related to CSENS treatments, as confirmed by uniform expression of $\beta$-actin.

CSENS treatments abrogate the transcriptional and DNA-binding activities of the $N F-x B$ and AP-1 proteins in HCT116 cells

Constitutive activation of NF- $x \mathrm{~B}$ was observed in colon cancer (Lind et al., 2001). Therefore, we investigated whether CSENS could suppress the activity of luciferase reporter driven by NF- $x$ B-response elements. HCT116 cells were transiently transfected with NF- $x$ B-regulated luciferase reporter construct; the cells were treated with increasing doses of CSENS and the basal activity of the reporter construct was assayed. The findings of these assays demonstrated that CSENS treatment, dose-dependently inhibited the transcriptional activity of the reporter driven by NF- $x \mathrm{~B}$ (Figure 6A). NF$\varkappa \mathrm{B}$ is known to be stimulated by MAP kinase pathway. Thus, we co-transfected HCT116 cells with the NF- $x \mathrm{~B}$ reporter construct along with an upstream kinase (MEKK) expression construct (pFC-MEKK). We observed that CSENS consistently inhibited the activity of the reporter (Figure 6B). These experiments indicate that CSENS treatment has the potentiality to abolish constitutive as well as MEKK-inducible transcriptional activities of NF- $x \mathrm{~B}$ in HCT116 cells. To elucidate the mechanism underlying the suppression of NF- $\varkappa \mathrm{B}$ activity by CSENS treatments, we tested whether CSENS modulates the binding of p65 subunit to the NF- $x \mathrm{~B}$ DNA response element. The cells were treated with CSENS, then nuclear lysates were prepared and a colorimetric p65 transcription factor assay was used to assess the amount of nuclear p65 bound to the consensus NF- $x$ B response element immobilized on the assay plate. As shown in Figure $6 \mathrm{C}$, CSENS, dose-dependently, noticeably abrogated the DNA-binding activity of p65 subunit. Therefore, we concluded that abrogating the transcriptional activity of $\mathrm{NF}-x \mathrm{~B}$ by CSENS is due to the inhibition of binding $\mathrm{p} 65$ subunit to DNA.

Next, we examined the effect of CSENS on the basal and MEKK-stimulating transcriptional activity of a reporter gene directed by AP-1-response element. We noticed that CSENS inhibited both the constitutive and MEKK-inducible activities of AP-1 (Figure 6D and E). Thus, we investigated whether CSENS modulates the binding of AP-1 protein to its response elements. The AP-1 molecule encompasses heterodimeric protein complexes including products of the Jun D and c-Fos genes (Hess et al., 2004). We tested whether CSENS treatments affect the DNA-binding activities of the AP-1 heterodimers, c-Fos and Jun D using colorimetric assays of c-Fos and Jun D transcription factors. The data generated from these experiments indicate that CSENS inhibited the DNAbinding activities of both AP-1 heterodimers (Figure $6 \mathrm{~F}$ and $\mathrm{G})$.

Finally, we examined the effects of CSENS on the expression and activities of genes known to be downstream effectors of the NF- $\mathrm{KB}$ and AP-1 and involved in cell survival or apoptosis pathways, including c-Myc, cyclin D1 and survivin. As displayed in Figure $6 \mathrm{H}$, CSENS treatments apparently decreased mRNA expression levels of all these genes, in a dose-dependent manner. Collectively, these findings indicate that CSENS treatments modulated the molecular and cellular pathways relevant to $\mathrm{CRC}$ carcinogenesis, leading to the inhibition of HCT116 cell growth.

\section{CSENS enhances the transcriptional and DNA-binding} activities of $\mathrm{Nrf} 2$

Many bioactive agents are known to exert their chemopreventive roles through the induction of Nrf2, a master regulator of ARE genes that mediate the expression of antioxidant/phase II detoxifying enzymes (Surh et al., 2008). Therefore, we investigated whether CSENS has an ability to stimulate the transcription activity of a reporter gene driven by ARE. Cells were transiently transfected with ARE-regulated luciferase reporter gene, treated with increasing doses of CSENS, and then the expression level of luciferase was monitored. As shown in Figure7A, CSENS treatments caused dose-dependent induction of ARE-regulated luciferase reporter. To further corroborate the positive effects of CSENS on the regulation of Nrf2 activity, we prepared nuclear extracts from cells treated with increasing concentration of CSENS and we assessed the amount of Nrf 2 bound to the consensus ARE immobilized on the assay plate. We observed an increase in florescence intensity paralleling the increase in CSENS dose, indicating that CSENS has a positive impact on binding Nrf2 to its response elements (Figure 7A). To confirm this conclusion, we assessed the expression

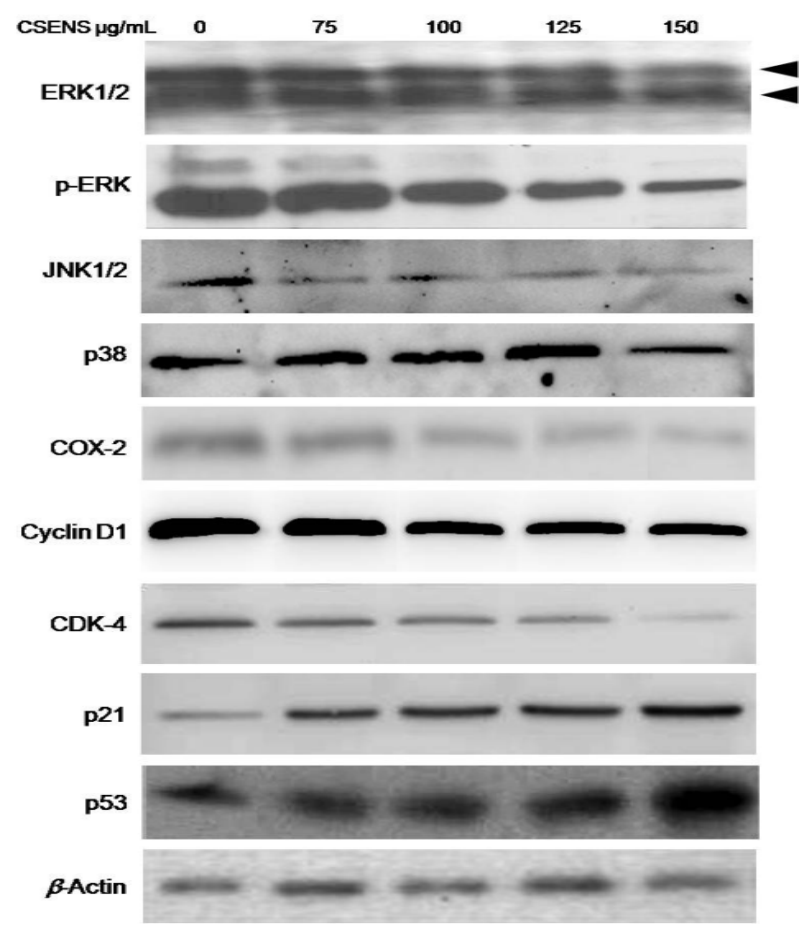

Figure 8. CSENS Modulated Expression Pattern of the Cell Cycle-Regulating proteins. HCT116 cells were treated with indicated concentrations of CSENS for $24 \mathrm{~h}$ and assayed as detailed in MATERIALS AND METHODS. Immunoblots show effect of CSENS on the displayed proteins. 
levels of the Nrf2 down-stream targets after CSENS treatments. We observed that CSENS dose-dependently induced the expression levels of Hemeoxygenase (HO-1), $\mathrm{NAD}(\mathrm{P}) \mathrm{H}$ quinine oxidoreductase 1 (NQO1) and UDPglucuronyltransferase (UGT1A1) (Figure 7B).

\section{Effect of CSENS on the expression of cell cycle related proteins}

It has been reported that the over-expression and activation of the MAPK pathway, notably ERK $1 / 2$ cascade, play a central role in the progression of CRC (see Discussion), so we examined the possible involvement of the ERK1/2 MAPK pathway in HCT116 cells treated with CSENS. As shown in Figure 8, CSENS significantly inhibited the activation of ERK1/2 (phosphorylated isoform) in a dose-dependent manner. Next, we assessed the effect of CSENS on the expression levels of key regulators of the cell cycle, including cyclin D1, cyclindependent kinase-4 (CDK-4), p21 and p53. Figure 8 demonstrates that CSENS consistently down-regulated the expression of cyclin D1 and CDK-4, in a dose-dependent manner, while it promoted the expression of p21 and p53. Collectively, these results indicate that cyclin D1, CDK-4, p21 and p53 genes are targets of CSENS.

\section{Discussion}

The treatment options for advanced CRC are limited due to drug resistance and side effects (Macdonald and Astrow, 2001; Rabik and Dolan, 2007). Therefore, there has been substantial interest in the search for potential chemopreventive agents for the treatment of CRC. The discovery and use of active medicinal compounds from herbal/natural sources have provided alternative remedies for CRC treatment (Aggarwal et al., 2009). Among natural herbs, N. sativa has been used for medicinal purposes as a natural remedy for a number of disorders including cancerous growths (Ahmad et al., 2013). It has been found that the most active component in N. sativa, is a phenolic compound, thymoquinone (Ahmad et al., 2013). Despite thymoquinone's generally low toxicity, it exhibits weak antitumor effects in numerous cancer-cell studies and animal models (Badary et al., 2001; Badary et al., 199; Gali-Muhtasib et al., 2006; 2008). In addition, some in vitro and in vivo experiments have demonstrated that thymoquinone has oxidative effects and genotoxic properties as it is metabolized to reactive species, which lead to DNA damage (Harzallah et ., 2012; Khader et al., 2009). Therefore, there is an urgent demand to search for a novel agent with fewer side effects. Notably and unwittingly, this study led to the examination of the effect of crude saponin extract prepared from N. sativa on the growth of the CRC cell line, HCT116. However, no study addressing the anticancer potentiality of $\mathrm{N}$. sativa'ssaponins on HCT116 cells has been reported yet. Saponins are widely known for their wide range of activities including antimicrobial, antidiabetic, cytotoxic, phytotoxic, antioxidant, antispasmodic and as anthelmintic (Guclu-Ustundag et al., 2007). Accumulative studies found that crude saponins have anti-cancer activities inin vitro and in vivomodels. Moreover, several saponins have been found to inhibit tumor cell growth by cell cycle arrest and apoptosis with $\mathrm{IC}_{50}$ values up to $0.2 \mathrm{mM}$. In addition, a combination of saponins with conventional tumor treatment strategies improved the therapeutic index in cancer therapy (Man et al., 2010).

A hallmark of colon carcinogenesis, as well as other cancer phenotypes, is enhanced cell proliferation and ablation of apoptosis (Huerta et al., 2006; Yang et al., 2009). In the present study, we have demonstrated for the first time that CSENS suppressed colon cancer cell proliferation and induced apoptosis, in a dose- and timedependent manner. On the other hand, crude flavonoid or alkaloid extract prepared from N. sativa had trivial effect on the growth of HCT116 cells. These observations suggest that the growth inhibitory potentiality of the CSENS is not fortuitous and raises a possibility that a specific component(s) in CSENS target(s) the growth of HCT116 cells. Furthermore, CSENS suppressed the growth of human hepatocellular carcinoma (HepG2) and breast cancer (MCF-7) cell lines, indicating that the cytotoxic effect of CSENS is not restricted to colon cancer cells, but extends to a wide range of cancerous lines. In contrast, CSENS had no significant effect on nonmalignant human fibroblasts (HF-5 cells), which raises the possibility that CSENS may selectively target colon cancer cells. These findings deserve attention because selectivity toward cancer cells is a highly advantageous feature of potential cancer chemopreventive and therapeutic agents. However, the experiments described here cannot exclude the possibility of tissue-specific differences between human fibroblasts and colon cancer cells. Additional cytotoxicity studies using a normal colon cell line and different colon cancer cell lines, as well as studies in vivo in nude mice are necessary to prove that CSENS can inhibit tumor growth without major side effects. A further proof of the anti-proliferation potentiality of CSENS was concluded from colony findings showing that CSENS efficiently ablated potentialities of the HCT116 cells to form colonies and to grow on agar medium. Because these assays measure the ability of tumor cells to grow and form foci in a manner unrestricted by growth contact inhibition as is characteristically found in normal, untransformed cells, therefore, these assays are further evidence demonstrating the anti-cancerous potentialities of CSENS. Thus, in the present study, we have identified a novel dietary agent, CSENS, which exhibited a highly anti-proliferative effect and efficiently inhibited the formation of colonies in CRC cells.

Next, we elucidated the molecular mechanism underlying the anti-proliferative potentiality of CSENS. It is highly accepted that apoptosis and/or necrosis are among the key mechanisms by which most anticancer agents exert their cytotoxic effects. To address whether the cell death induced by CSENS could be due to apoptosis, we ascertained the apoptogenecity of CSENS by Annexin V FITC/PI dual staining. This assay was based on the fact that phosphatidylserine (PS)] localized to the cytoplasmic face of the cell membrane in healthy cells, translocates to the extracellular face of the cell membrane in apoptotic cells. This translocation process occurs relatively at early stage of apoptosis and can be detected by binding 
Annexin V to translocated PS, which makes it a marker for assessing early stages of apoptosis. During late apoptosis or necrosis, membrane integrity is lost; therefore, PI also enters the cell through damaged membranes, binds to cellular DNA and stains the nucleus red. Therefore, Annexin V FITC/PI assay helps to distinguish between apoptotic and necrotic cell death. The flow cytometry analyses demonstrated that the percentage of cells stained with Annexin V and PI increased with the increasing concentrations of CSENS. Because the rupture of the cellular membrane is one of the crucial criteria used to distinguish necrosis from apoptosis (Kim et al., 2001), thus, it seems that the cell membrane was disrupted and the cells died by necrosis at higher concentrations of CSENS exposure. Based on this, we report that the cytotoxic efficacy of CSENS in HCT116 cells may be associated, at least in part, with apoptosis accompanied by secondary necrotic cell death probably due to the loss of membrane integrity. The fact that high doses of CSENS triggered necrotic cell death does not argue with its potentiality as a promising chemopreventive agent, as it has been reported that with increasing concentration or exposure time of the cytotoxic agents, cell death changes its type from apoptotic to necrotic (Sun et al., 2006; Han et al., 2007). In addition, some recent studies advocate that necrosis could be an alternative form of cell death when apoptotic pathways are impaired, as seen in cancer cells, and the agents having potentiality to induce necrosis could be promising chemotherapeutics to circumvent the impaired apoptotic pathways found in cancer cells (Sun et al., 2006; Han et al., 2007).

Consistent with the observation from flow cytometry, microscopic inspections revealed an abundance of morphological alterations characteristic to programmed cell death in CSENS-treated cells. These alterations were dose-dependent and included loss of cell viability, cell shrinkage, irregularity in cellular shape, cellular detachment, chromatin condensation and eventual cleavage of the nucleus and cytoplasm into multiple membrane-enclosed bodies called apoptotic bodies. The $\mathrm{AO} /$ Et double staining displayed predominance of the red color at the highest dose of CSENS, which parallels the findings from flow cytometric analyses and suggests an incidence of late apoptotic death associated with secondary necrotic cell death.

Genomic lesions due to the activation of the DNA damage response were detected by comet assay, where CSENS treatments resulted in the formation of comet tail. It has been reported that comet assay is more sensitive than DNA ladder assay in detecting DNA damage and distinguishes apoptosis from necrosis, which makes it a reliable assay for the detection of programmed cell death (Yasuhara et al., 2003). This assay was originally developed for measuring DNA damage of cells exposed to any genotoxic agents (Collins, 2002). However, the comet image generated by apoptotic agents is different from that obtained with a cell treated with genotoxic agents. The comet head formed by apoptotic agents is characterized by the presence of apoptotic bodies, which are not seen in genotoxic comet. Therefore, we characterized and analyzed the different features of comet images induced by CSENS with those generated by known genotoxic agents, $\mathrm{H} 2 \mathrm{O} 2$ and Benzo(a)pyrene (Kirilova et al., 2005). We did observe CSENS, but not $\mathrm{H} 2 \mathrm{O} 2$ or Benzo(a)pyrene, induced DNA comet tail and head images typical of apoptosis-inducing agents. Therefore, the results of comet assay add a further proof that CSENS treatments mediated DNA damage in HCT116 cells. Cells with damaged DNA could undergo apoptosis if the damage can hardly be repaired, therefore, the observation of these assays suggests that CSENS treatments might trigger events leading to DNA damage and initiation of apoptotic cascade, which may contribute, at least in part, to the diminution of cell viability in HCT116.

It has been suggested that there are two redundant parallel pathways that lead to chromatin processing during apoptosis (Susin et al., 2000). One of these involves the activation of caspases, and eventual oligonucleosomal DNA fragmentation (Samejima et al., 1998). The other engages translocation of the mitochondrial protein (AIF) to the nucleus resulting in peripheral chromatin condensation and large-scale DNA fragmentation, with a size of $~ 50$ kbp (Broker et al., 2005). Treatment of HCT116 cells with CSENS resulted in chromatin condensation, as shown by vital nuclear stain (Hoechst 33342), but it did not produce oligonucleosomal DNA fragmentation. In contrast, treatment of HCT116 cells with crude alkaloid extract prepared from other medicinal herb called Rhazya stricta resulted in the formation of a classical oligonucleosomal DNA ladder, demonstrating that the failure to detect oligonucleosomal DNA fragmentation in response to CSENS was not due to an inherent impairment in the classical apoptotic cascade in HCT116 cells. Therefore, these results suggest that CSENS has a potentiality to induce apoptosis, but it does not implement classical apoptotic pathway to process DNA during apoptosis. A further support to this conclusion was driven from the result showing the null activation of caspase- 3 after treatment of cells with CSENS. It is generally accepted that the activation of caspase- 3 is a key step that provokes down-stream events mediating oligonucleosomal DNA fragmentation, cleavage of proteins essential for cell viability and morphological hallmarks of apoptosis[11]. However, increasing bodies of evidence support the notion of caspase-independent programmed cell death pathways, where caspase activation and other markers of classical apoptosis are completely absent (Broker et al., 2005). This caspase-independent pathway manifests peripheral chromatin condensation and large-scale (i.e. non-oligonucleosomal) DNA fragmentation (Susin et al., 2000), which may explain why we could not see DNA fragmentation or caspase-3 activation. The induction of programmed cell death without caspase activation or DNA fragmentation has been attributed to other chemotherapeutic agents, such as curcumin and Matrine (Cipriani et al., 2001; Zhou et al., 2014). Similar to these agents, it seems that CSENS bestows, as yet unknown, caspase-independent pathway to impose its apoptogenic potentiality.

$\mathrm{NF}-x \mathrm{~B}$ and $\mathrm{AP}-1$ are pleiotropic transcription factors emerging as important targets in the pathogenesis of colon cancer. These two transcription factors are reported to play 
a synergistic role in many biological processes and crosscoupling of these transcription factors has been reported (Glinghammer and Rafter, 2002). The NF- $x \mathrm{~B}$ family of transcription factors exists as homo- and heterodimers; the most commonly encountered dimer in mammalian cells is the p65/p50 dimer (Pereira and Oakley, 2008). In most normal cells, the p65/p50 dimer is retained in the cytoplasm as an inactive complex by means of direct binding with specific inhibitors. Upon activation by molecular cues, NF- $x \mathrm{~B}$ dimer migrates to the nucleus, where it binds to a common DNA sequence, the $x \mathrm{~B}$-site, within the enhancer elements of the NF- $x \mathrm{~B}$ target genes and promotes transcription (Pereira and Oakley, 2008). Contrary to this scenario, NF- $x \mathrm{~B}$ has been found to be constitutively activated in colon cancer and the sustained activation of NF- $x \mathrm{~B}$ underlies resistance of CRC cells to the apoptosis induced by various chemotherapeutic agents (Yun et al., 2009). Thereby, agents that can suppress NF$\varkappa \mathrm{B}$ activation have the ability to suppress carcinogenesis and thus, have therapeutic potential (Aggarwal and Shishodia, 2006). Consistent with this notion, several phytochemicals, such as curcumin, resveratrol, and others, have been found to mediate their chemopreventive effects through the suppression of NF- $x \mathrm{~B}$ activation (Su et al., 2006). All these studies prompted us to address whether CSENS affects the activity of NF- $\varkappa$ B in HCT116 cells; in particular, we tested whether CSENS decreases the activity of a luciferase reporter gene driven by NF- $x \mathrm{~B}$ response elements. The data herein demonstrate that CSENS suppressed the activity of the reporter gene. In addition, when we transfected cells with NF- $\varkappa$ B-driven luciferase reporter along with MEKK expression construct, which induces the activity of NF- $x \mathrm{~B}$, we obtained parallel results, luciferase inhibition, indicating that CSENS negatively modulated constitutive and MEKK-dependent inducible activities of the NF- $x$ B. The mechanism whereby CSENS inhibits NF- $x \mathrm{~B}$ activity was further investigated. The NF- $x$ B dimer ( $\mathrm{p} 50 / 65$ ) binds to its DNA element via the p65 subunit; we found that CSENS abrogated the DNAbinding activity of p65. Therefore, it is possible that an ingredient(s) found in CSENS formed an adduct with p65, resulting in the alteration of p65 properties, including DNA binding activity. Similar to CSENS, curcumin has been found to induce apoptosis in human colon cancer cells through the inhibition of NF- $x \mathrm{~B}$ activation (Su et al., 2006).

AP-1 is composed of a mixture of heterodimeric complexes of protein families, including Fos and Jun (Hess et al., 2004). AP-1 is involved in CRC pathogenesis[10]; high concentrations of bile acids induce AP-1 expression resulting in the stimulation of COX-2 that mediates antiapoptosis, motility and invasion (Debruyne et al., 2001). Several phytochemicals, such as green tea resveratrol, curcumin, $\beta$-lapachone and others have been shown to exert their chemo-therapeutic potentialities via suppressing the AP-1 activation process (AggarwalandShishodia, 2006; Debruyne et al., 2001). We investigated the transactivation of the AP-1 luciferase reporter in HCT116 cells treated by CSENS and we found that CSENS treatment suppressed, in a dose-dependent manner, the transcriptional activity of AP-1. This observation was correlated with a decrease in DNA-binding activities of two Ap-1 subunits, c-Fos and Jun D. Therefore, one of the seminal findings in the current study is that CSENS treatment targeted survival signaling pathways regulated by $\mathrm{NF}-\varkappa \mathrm{B}$ and $\mathrm{AP}-1$, which could boost the pro-apoptotic effect of CSENS leading to growth-inhibition in HCT116 cells.

One of the most prominent strategies of cancer chemoprevention counts on protecting cells/tissues against various carcinogens and carcinogenic metabolites that could come from exogenous and/or endogenous sources. This could be achieved via induction of phase II detoxifying/anti-oxidant enzymes expressed by cytoprotective genes (Eggler et al., 2008). These genes are controlled by an ARE enhancer and Nrf2 protein (Lee et al., 2004). Under basal condition, Nrf2 is sequestered in the cytoplasm as an inactive complex with a cytosolic inhibitor protein, Keap1. Exposure of cells to ARE inducers results in the dissociation of Nrf2 from Keap1 and translocation of Nrf2 to the nucleus, where it activates the expression ARE-dependent genes (Yu and Kensler, 2005). Various phytochemicals have been found to mediate the activation of ARE-regulated genes through the induction of Nrf2 signaling (Surh et al., 2008).Furthermore, several chemopreventive agents have been found to exert their anti-carcinogenic effect through the activation of Nrf2ARE pathway and attenuation of NF- $x$ B signaling (Bellezza et al., 2010; Yu and Kensler, 2005). The results herein demonstrate that CSENS treatments increased DNA binding, and consequently, transactivation activities of Nrf2. Therefore, these data hint at a point that CSENS has this dichotomous potentiality, the activation of Nrf2 and attenuation of NF- $x \mathrm{~B}$, which may maximize CSENS chemopreventive efficacy.

The MAPK signaling pathway is a family of signal transduction proteins that couples signals from cell surface receptors to the intracellular machineries, which control fundamental cellular processes, such as gene expression, growth, proliferation, differentiation and apoptosis (Pearson et al., 2001). The MAPK cascade comprises three main subdivisions, namely $(i)$ extracellular signalrelated kinases 1 and 2(ERK1/2), (ii) c-JUN N-terminal kinase (JNK) 1, 2, and 3, and (iii) p38-MAPK (Pearson et al., 2001). Several lines of evidence suggest that the activation of the MAPK pathway, in particular ERK MAPK cascade, plays an important role in the pathogenesis, progression, and oncogenic behavior of human CRC (Fang and Richardson, 2005). Therefore, strategies to block the activity of ERK would ideally lead to the inhibition of proliferation and induction of apoptosis in CRC. Consistent with this notion, a growing list of phytochemicals has been found to modulate the ERK1/2 pathway and to inhibit the progression of adenoma to adenocarcinoma in vivo via a down-regulation of ERK1/2 activity (Prouillet et al., 2004; Lu et al., 2006; ; Wruck et al., 2007; Corona et al., 2009). Activation of ERK1/2 pathway promotes cell cycle progression and division (Wright et al., 1999), at least in part, through the induction of cyclin D1 expression (Lavoie et al., 1996; Lee et al., 2006). The elevated expression level of cyclinD1 forms a complex with a family of serine/threonine protein kinases, cyclin-dependent kinases-4/6 (CDK-4/6); this cyclin D1/ 
Nigella sativa Extract Inhibits Proliferation and Enhances Apoptosis of Colon Cancer Cells

CDK-4/6 complex initiates events that facilitate transition through the restriction point in the G1 phase (Ekholm and Reed, 2000). Therefore, over-expressed or hyper-activated cyclin D1/CDK-4/6 complex often leads to uncontrolled cell division and malignancy (Kouraklis et al., 2006). Consequently, the role of cyclin D1 and CDK-4 in the evolution and progression of CRC has been documented (Arber et al., 1997; Hogan et al., 2007; Karim et al., 2013; Shan et al., 2009). The activity of the cyclin D1/CDK-4/6 complex is counteracted by cell cycle inhibitory proteins, p21WAF1/CIP1 and p27KIP1, which block the G1 to S phase transition via binding to $\mathrm{CDK}-4$, thereby resulting in a G0-G1 phase arrest of the cell cycle (Vermeulen et al., 2003). Importantly, reduced p 21 protein level has been found to play an important role in the progression of colon cancer (Bukholm andNesland, 2000). In addition to cyclin/ CDK complexes, cell cycle progression is tightly regulated by other hub proteins, p53, a stress-inducible transcription factor that mediates the induction of cell cycle arrest and apoptosis following DNA damage or cellular stress in human cells (Hainaut and Wiman, 2009). p53 mutations are present in more than $50 \%$ of all cancers (Oren and Rotter, 2010) and have been found in approximately $40 \%-50 \%$ of sporadic CRC (Li et al., 2015). The Western blot analyses, herein, demonstrate that the inhibition of ERK1/2 phosphorylation by CSENS was paralleled by a reduction in cyclin D1 and CDK4 levels and a marked increase in the expression levels of p21 and p53. Based on these data, it is reasonable to speculate that CSENS has a potential to induce cell cycle arrest, which leads to a reduction in HCT116 cell number. Therefore, CSENS has the ability to induce apoptosis and cell cycle arrest in HCT116 cells, which highlights its potential to act as a therapeutic agent for the treatment of colonic cancer progression.

\section{Acknowledgements}

This study was funded by the King Abdulaziz City for Science and Technology (KACST), Riyadh, Saudi Arabia, under a research grant no "AT-32-66". The authors, therefore, acknowledge with thanks KACST technical and financial support.

\section{References}

Aggarwal B, Shishodia S (2006). Molecular targets of dietary agents for prevention and therapy of cancer. Bichemical Pharmacol, 71, 1397-421.

Aggarwal B, Van Kuiken ME, Iyer LH, et al (2009). Molecular targets of nutraceuticals derived from dietary spices: potential role in suppression of inflammation and tumorigenesis. Exp Biol Med, 234, 825-49.

Ahmad A, Husain A, Mujeeb M, et al (2013). Review on therapeutic potential of nigella sativa: a miracle herb. Asian Pac J Trop Biomed, 3, 337-52.

Ali BH, Blunden G (2003). Pharmacological and toxicological properties of nigella sativa. Phytother Res, 17, 299-305.

Arber N, Doki Y, Han EK, et al (1997), Antisense to cyclin D1 inhibits the growth and tumorigenicity of human colon cancer cells. Cancer Res, 57, 1569-74.

Assim MR, Shahzad M, Yang X, et al (2010). Suppressive effects of black seed oil on ovalbumin induced acute lung remodeling in E3 rats. Swiss Med Wkly, 140, 13128.

Badary OA, Gamal El-Din AM (2001). Inhibitory effects of thymoquinone against 20 methyl cholanthrene induced fibrosarcoma tumorigenesis. Cancer Detect Prev, 25, 362-8.

Badary OA, Al-Shabanah OA, Nagi MN, et al (1999). Inhibition of benzo(a)pyrene induced fore-stomach carcinogenesis in rats by thymoquinone. Eur J Cancer Prev, 8, 435-40.

Banerjee S, Padhye S, Azmi A, et al (2010). Review on molecular and therapeutic potential of thymoquinone in cancer. Nutr Cancer, 62, 938-46.

Bellezza I, Mierla AL, Minelli A (2010). Nrf2 and NF- $\varkappa$ B and their concerted modulation in cancer pathogenesis and progression. Cancers, 2, 483-97.

Broker LE, Kruyt, FA, Giaccone G (2005). Cell death independent of caspases: a review. Clin Cancer Res, 11, 3155-62.

Bukholm IK, Nesland JM (2000). Protein expression of p53, p21 (WAF1/CIP1), bcl-2, Bax, cyclin D1 and pRb in human colon carcinomas. Virchows Arch, 436, 224-8.

Chakraborty S, Kundu T, Dey S, et al (2006). Tea-induced apoptosis in human leukemia K562 cells as assessed by comet formation. Asian Pac J Cancer Prev, 7, 201-7.

Cipriani B, Borsellino G, Knowles H, et al (2001). Curcumin inhibits activation of $\mathrm{V} \gamma 9 \mathrm{~V} \delta 2 \mathrm{~T}$ cells by phosphoantigens and induces apoptosis involving apoptosis-inducing factor and large scale DNA fragmentation. J Immunol, 167, 345462.

Collins AR (2002). Comet assay: principles, applications, and limitations. Methods Mol Biol, 203, 163-177.

Corona G, Deiana M, Incani A, et al (2009). Hydroxytyrosol inhibits the proliferation of human colon adenocarcinoma cells through inhibition of ERK1/2 and cyclin D1. Mol Nutr Food Res, 53, 897-903.

Debruyne PR, Bruyneel EA, Li X, et al (2001). The role of bile acids in carcinogenesis. Mutat Res, 480-481, 359-69.

Eggler AL, Gay KA, Mesecar AD (2008). Molecular mechanisms of natural products in chemoprevention: Induction of cytoprotective enzymes by Nrf2. Mol Nutr Food Res, 52, 84-94.

Ekholm SV, Reed SI (2000). Regulation of G(1) cyclindependent kinases in the mammalian cell cycle. Curr Opin Cell Biol, 12, 676-84.

Elkady AI, El-Hamidy MS (2013). Induction of growth arrest and apoptosis in human lung cancer cells by crude saponin extract isolated from nigella sativa. Life Science J, $\mathbf{1 0}$.

Elkady AI (2013). Crude alkaloid extract of rhazyastricta inhibits proliferation and sensitizes human lung cancer cells to cisplatin through induction of apoptosis. Genet Mol Biol, 36, 12-21.

Elkady AI, Hussein RA, Abu-Zinadah AO (2014). Differential control of growth, apoptotic activity and gene expression in human colon cancer cells by extracts derived from medicinal herbs, rhazya stricta and zingiber officinale and their combination. World J Gastroenterol, 20, 15275-88.

Fang JY, Richardson BC (2005). The MAPK signaling pathways and colorectal cancer. Lancet Oncol, 6, 322-7.

Fulda S, Debatin KM (2004). Targeting apoptosis pathways in cancer therapy. Curr Cancer Drug Targets, 4, 569-76.

Gañán-Gómez I, Wei Y, Yang H, et al (2013). Oncogenic functions of the transcription factor Nrf2. Free Radical Biol Med, 65, 750-64.

Gali-Muhtasib H, Roessner A, Schneider-Stock R (2006). Thymoquinone: a promising anti-cancer drug from natural sources. Int J Biochem Cell Biol, 38, 1249-53.

Gao JL, Lv GY, He BC, et al (2013). Ginsengsaponin metabolite 20 (S)-protopanaxadiol inhibits tumor growth by targeting 
multiple cancer signaling pathways. Oncol Rep, 30, 292-8.

Glinghammer HI, Rafter JJ (2002). Deoxycholic acid causes DNA damage in colonic cells with subsequent induction of caspases, COX-2 promotor activity and the transcription factor NF- $x \mathrm{~B}$ and AP-1. Carcinogenesis, 23, 839-45.

Gopalakrishnan A, Kong AT (2008). Anticarcinogenesis by dietary phytochemicals: Cytoprotection by Nrf2 in normal cells and cytotoxicity by modulation of transcription factors NF- $x$ B and AP-1 in abnormal cancer cells. Food Chemical Toxicol, 46, 1257-70.

Guclu-Ustundag O, Mazza G (2007). Saponins: Properties, Applications and Processing. Critical Rev Food Science Nutrit, 47, 231-58.

Gurfinkel M, Rao AV (2003). Soya saponins: the relationship between chemical structure and colon anticarcinogenic activity. Nutr Cancer, 47, 24-33.

Han W, Li L, Qiu S, et al (2007). Shikonin circumvents cancer drug resistance by induction of a necroptotic death. $\mathrm{Mol}$ Cancer Ther, 6, 1641-9.

Hainaut P, Wiman KG (2009). 30 years and a long way into p53 research. Lancet Oncol, 10, 913-9.

Hess J, Angel P, Schorpp-Kistner M (2004). AP-1 subunits: quarrel and harmony among siblings. J Cell Sci, 117, 5965-73.

Hogan FS, Krishnegowda NK, Mikhailova M, et al (2007). Flavonoid, silibinin, inhibits proliferation and promotes cellcycle arrest of human colon cancer. J Surg Res, 143, 58-65.

Hsu TC, Young MR, Cmarik J, et al (2000). Activator protein 1 (AP-1)- and nuclear factor kappaB (NF-kappaB)-dependent transcriptional events in carcinogenesis. Free RadicBiol Med, 28, 1338-48.

Jemal A, Siegel R, Xu J, et al (2010). Cancer statistics. $C A$ Cancer J Clin, 60, 277-300.

Karim BO, Rhee KJ, Liu G, et al (2013). Chemoprevention utility of silibinin and Cdk4 pathway inhibition in $\operatorname{Apc}(-/+)$ mice. BMC Cancer, 13, 157.

Khader M, Bresgen N, Eckl PM (2009). In vitro toxicological properties of thymoquinone. Food Chem Toxicol, 47, 129-33.

Khan N, Afaq F, Mukhtar H (2006). Apoptosis by dietary factors: the suicide solution for delaying cancer growth. Carcinogenesis, 28, 233-9.

Khan A, Chen H-C, Tania M, et al (2011). Anticancer activities of Nigella sativa (black cumin). Afr J Tradit Complement Alter. Afr J Tradit Complement Altern Med, 8, 226-32.

Kim H, You S, Kong B, et al (2001). Necrotic cell death by hydrogen peroxide in immortal DF-1 chicken embryo fibroblast cells expressing deregulated MnSOD and catalase. Biochimca et Biophysica Acta, 1540, 137-46.

Kirilova M, Ivanov R, Miloshev GA (2005). Novel Parameter In Comet Assay Measurements. Genetika, 37, 93-101.

Kouraklis G, Theocharis S, Vamvakas P, et al (2006). Cyclin $\mathrm{D} 1 \mathrm{and} \mathrm{Rb}$ protein expression and their correlation with prognosis in patients with colon cancer. World J Surg Oncol, 4, 5.

Kundu JK, Surh YJ (2004). Molecular basis of chemoprevention by resveratrol: NF-kappaB and AP-1 as potential targets. Mutat Res, 555, 65-80.

Lavoie JN, L'Allemain G, Brunet A, et al (1996). Cyclin D1 expression is regulated positively by the $\mathrm{p} 42 / \mathrm{p} 44 \mathrm{MAPK}$ and negatively by the p38/HOGMAPK pathway. J Biol Chem, 271, 20608-16.

Lee J-M, Johnson JA (2004). An important role of Nrf2-ARE pathway in the cellular defense mechanism. J Biochem Molecular Biol, 37, 139-43.

Lee SY, Munerol B, Pollard S, et al (2006). The reaction of flavanols with nitrous acid protects against nitrosamine formation and leads to the formation of nitroso derivatives which inhibit cancer cell growth, Free RadicBiol Med, 40, $323-34$.

Li XL, Zhou J, Chen ZR, et al (2015). p53 mutations in colorectal cancer- molecular pathogenesis and pharmacological reactivation. World J Gastroenterol, 21, 84-93.

Lind DS, Hochwald SN, Malaty J, et al (2001). Nuclear factor$x \mathrm{~B}$ is upregulated in colorectal cancer. Surgery, 130,363-9.

Lu G, Liao J, Yang G, et al (2006). Inhibition of adenoma progression to adenocarcinoma in a 4-(methylnitrosamino)1-(3-pyridyl)-1-butanone-induced lung tumorigenesis model in $\mathrm{A} / \mathrm{J}$ mice by tea polyphenols and caffeine. Cancer Res, 66, 11494-501.

Macdonald JS, Astrow AB (2001). Adjuvant therapy of colon cancer. Semin Oncol, 28, 30-40.

Man S, Gao W, Zhang Y, et al (2010). Chemical study and medical application of saponins as anti-cancer agents. Fitoterapia, 81, 703-14.

Martin KR (2006). Targeting Apoptosis with Dietary Bioactive Agents. Exp Biol Med, 231, 117-29.

Nagata S (2000). Apoptotic DNA fragmentation. Exp Cell Res, 256, $12-8$.

Oren M, Rotter V (2010). Mutant p53 gain-of-function in cancer. Cold Spring Harb Perspect Biol, 2, 1107.

Pearson G, Robinson F, Beers GT, et al (2001). Mitogenactivated protein (MAP) kinase pathways: regulation and physiological functions. Endocr Rev, 22, 153-83.

Pereira SG, Oakley F (2008). Nuclear factor- $x$ B1: Regulation and function. Int J Biochem Cell Biol, 40, 1425-30.

Prouillet C, Maziere JC, Maziere C, et al (2004). Stimulatory effect of naturally occurring flavonolsquercetin and kaempferol on alkaline phosphatase activity in MG-63 human osteoblasts through ERK and estrogen receptor pathway. Biochem Pharmacol, 67, 1307 -13.

Rabik CA, Dolan ME (2007). Molecular mechanisms of resistance and toxicity associated with platinating agents. Cancer Treat Rev, 33, 9-23.

Samejima K, Tone S, Kottke TJ, et al (1998). Transition from caspase-dependent to caspase-independent mechanisms at the onset of apoptotic execution. J Cell Biol, 143, 225-39.

Schulz, WA. Molecular biology of human cancers: an advanced student's textbook. Springer Science \& Business Media, 2005. Springer Dordrecht, Netherlands.

Seeram NP, Adams LS, Hardy ML, et al (2004). Total cranberry extract versus its phytochemical constituents: antiproliferative and synergistic effects against human tumor cell lines. J Agric Food Chem, 52, 2512-7.

Seeram NP, Adams LS, Henning SM, et al (2006). In vitro antiproliferative, apoptotic and antioxidant activities of punicalagin, ellagic acid and a total pomegranate tannin extract are enhanced in combination with other polyphenols as found in pomegranate juice. J Nutr Biochem, 16, 360-7.

Shan BE, Wang MX, Li RQ (2009). Quercetin inhibit human SW480 colon cancer growth in association with inhibition of cyclin D1 and survivin expression through Wnt/beta-catenin signaling pathway. Cancer Invest, 27, 604-612.

Su CC, Chen GW, Lin LG, et al (2006). Curcumin inhibits cell migration of human colon cancer colo-205 cells through the inhibition of nuclear factor kappaB/p65 and downregulates cyclooxygenase- 2 and matrix metalloproteinase- 2 expressions. Anticancer Res, 26, 1281-8.

Sun X, Li Y, Li W, et al (2006). Selective induction of necrotic cell death in cancer cells by beta-lapachone through activation of DNA damage response pathway. Cell Cycle, 5, 2029-35.

Surh YJ, Kundu JK, Na HK (2008). Nrf2 as a master redox switch in turning on the cellular signaling involved in the induction of cytoprotective genes by some chemopreventive 
phytochemicals. Planta Med, 74, 1526-39.

Susin SA, Daugas E, Ravagnan L, et al (2000). Two distinct pathways leading to nuclear apoptosis. J Exp Med, 192, $571-80$.

Trease GE, Evans WC (2002). Pharmcognosy, Editition 16, Saunder Elsevier, London, 135-47.

Vaiopoulos G, Papachroni K, Papavassiliou AG (2010). Colon carcinogenesis: Learning from $\mathrm{NF}-x \mathrm{~B}$ and $\mathrm{AP}-1$. Int $J$ Biochem Cell Biol, 42, 1061-5.

Vermeulen K, Van Bockstaele DR, Berneman ZN (2003). The cell cycle: a review of regulation, deregulation and therapeutic targets in cancer. Cell Prolif, 36, 131-49.

Wong RS (2011). Apoptosis in cancer: from pathogenesis to Treatment. J Exp Clin Cancer Res, 30, 87.

Wright JH, Munar E, Jameson DR, et al (1999). Mitogenactivated protein kinase kinase activity is required for the $\mathrm{G}(2) / \mathrm{M}$ transition of the cell cycle in mammalian fibroblasts. Proc Natl Acad Sci USA, 96, 11335-40.

Wruck CJ, Claussen M, Fuhrmann G, et al., (2007). Luteolin protects rat $\mathrm{PC} 12$ and $\mathrm{C} 6$ cells against $\mathrm{MPP}+$ induced toxicity via an ERK dependent Keap1-Nrf2-ARE pathway. J Neural Transm Suppl, 72, 57-67.

Yang SY, Sales KM, Fuller B, et al (2009). Apoptosis and colorectal cancer: implications for therapy. Trends $\mathrm{Mol}$ Med, 15, 225-33.

Yasuhara S, Zhu Y, Matsui T, et al (2003). Comparison of comet assay, electro nmicroscopy, and flow cytometry for detection of apoptosis. J Histochem Cytochem, 51, 873-85.

Yun J-M, Afaq F, Khan N, et al (2009). Delphinidin, an anthocyanidin in pigmented fruits and vegetables, induces apoptosis and cell cycle arrest in human colon cancer HCT116 cells. Molecular Carcinogenesis, 48, 260-70.

Yu X, Kensler T (2005). Nrf2 as a target for cancer chemoprevention. Mutat Res, 591, 93-102.

Zhou H, Xu M, Gao Y, et al (2014). Matrine induces caspaseindependent programcell death in hepatocellular carcinoma through bid-mediated nuclear translocation of apoptosis inducing factor. Molecular Cancer, 13, 59. 